\title{
Pregnancy outcome in extremes of reproductive age at a tertiary care hospital
}

\author{
Dias T, Wijesinghe E, Abeykoon S, Ganeshamoorthy P, Kumarasiri S, Kodithuwakku M, Gunewardena C, \\ Padeniya T
}

\begin{abstract}
Introduction: Pregnancy outcomes in teenagers and in elderly are independently associated with adverse outcomes. The aim of this study was to find out pregnancy outcome at extremes of reproductive age.

Methods: This was a retrospective cohort study conducted between April 2010 and October 2013 at a tertiary care hospital. Individual pregnancy records, delivery suite register and neonatal care unit records were traced in order to gather information. Mortality data were traced from respective units and cross checked with hospital monthly perinatal statistics. Outcome data were compared between teenage pregnancies and pregnancies at normal age (20-34). Same comparison was done for mothers with advanced maternal age.
\end{abstract}

Results: A total of 12477 pregnancies were included (teenage-1009, normal-10192, advanced maternal age-1276). Intra-uterine death (IUD) rate and early neonatal death rates were not significantly higher among teenagers compared to age group 20-34 (OR $0.57,95 \% \mathrm{Cl} 0.17$ to 1.83 and $\mathrm{OR} 2.53,95 \% \mathrm{Cl} 0.71$ to 8.97 respectively). Preterm birth rate was significantly high among teenagers (OR $1.33,95 \%, \mathrm{Cl} 1.12$ to 1.56 ). In mothers with advanced age, early neonatal death rate and caesarean section rate were significantly higher than the age group of $20-34$ (OR $3.3395 \% \mathrm{Cl} 1.17$ to 9.49 and OR $2.1795 \% \mathrm{Cl}$ 1.92 to 2.44 respectively). In contrast, caesarean section rate was low in teens (OR 0.44 $95 \% \mathrm{Cl} 0.36$ to 0.52 ). Stillbirth and preterm birth rates were not significantly different (OR $1.3695 \% \mathrm{Cl} 0.66$ to 2.76 and $\mathrm{OR} 0.9895 \% \mathrm{Cl} 0.83$ to 1.15 ) in mothers with advanced maternal age.

Conclusions: Risks of pregnancy complications are different from teens and in advanced maternal age. More studies are needed to establish the exact causes of these risks and evaluate management options in these women.

\section{Introduction}

Extreme reproductive age groups are broadly classified into teenage pregnancy $<20$ years and advanced maternal age pregnancy $>35$ year $^{1,2}$. Recent studies have shown both advanced maternal age and younger age pregnancies conferred to an

District General Hospital Ampara, Sri Lanka.

Correspondence: Tiran Dias

E-mail: thiran_dias@yahoo.com

Competing interests: None. increased risk of adverse pregnancy outcomes that was independent of important confounding socio-demographic factors ${ }^{3,4}$. Globally 15 million women under the age of 20 give birth, representing up to one-fifth of all births ${ }^{5}$. In the developing world, onethird to one-half of women become mothers before the age of 20 and pregnancy related complications have become the leading causes of death among them ${ }^{6,7}$. Recent decades have witnessed also an increase in mean maternal age at childbirth ${ }^{8}$. In women with advanced maternal age there is an increase in the number of miscarriages, ectopic pregnancies, and twinning 9 . Having a clear idea about what to anticipate during the pregnancy can help optimize antenatal care given to patients at these age groups and thus improve the overall outcome of the pregnancy. This information can also help to implement future health care policies and improve the health care system nationwide. The aim of this study was to find out about the pregnancy outcomes at extremes of maternal age.

\section{Methods}

This was a retrospective cohort studycarried out at a tertiary care hospital, from a period between April 2010 and October 2013. Details of the pregnancy were retrieved from antenatal, labour ward and postnatal records. Perinatal and mortality data were cross checked with the ward and hospital statistics. Pregnancy outcome of extremes of reproductive ages were compared with mothers aged 20-35 years of age at time of delivery. All pregnancies were dated by fetal crown-rump length before 14 weeks and by fetal head circumference thereafter ${ }^{10,11}$. All pregnancies were managed according to the ward protocol and the need of the patient. Ethics clearance was obtained from the District General Hospital Ampara ethics review committee.

\section{Results}

A total of 12477 pregnancies were included (teenage-1009, normal10192, advanced maternal age-1276). Basic and pregnancy outcome characteristics of the study population are given in table one and two respectively. Intra-uterine death (IUD) 
Table1. Basic characteristics of the study group

\begin{tabular}{lccc}
\hline & Teenage (12-19) & Normal (20-34) & Advanced maternal age (35-51) \\
\hline Total (\%) & $1009(8 \%)$ & $10192(81.7)$ & $1276(10.3 \%)$ \\
Mean age (SD) yrs & $18.4(0.8)$ & $26.7(3.9)$ & $37.1(2.02)$ \\
Primi (\%) & $939(93)$ & $3933(38.6)$ & $125(9.8)$ \\
Multi (\%) & $70(7)$ & $6259(61.4)$ & $1151(90.2)$ \\
\hline
\end{tabular}

Table 2. Outcome characteristics of the study group

\begin{tabular}{lccc}
\hline & Teenage (12-19) & Normal (20-34) & Advanced maternal age (35-51) \\
\hline Normal outcome & $1003 / 1009$ & $10111 / 10192$ & $1262 / 1276$ \\
IUD & 3 & 53 & 9 \\
END & 3 & 12 & 5 \\
LNND & 0 & 16 & 0 \\
Preterm deliveries & 210 & 1687 & 208 \\
Term deliveries & 899 & 8505 & 968 \\
NVD & 871 & 7472 & 715 \\
LSCS & 137 & 2701 & 560 \\
\hline
\end{tabular}

rate and early neonatal death rates were not significantly higher among teenagers compared to the age group of 20-34 (OR $0.57,95 \%$ CI 0.17 to 1.83 and OR $2.53,95 \%$ CI 0.71 to 8.97 respectively). Preterm birth rate was significantly high among teenagers (OR 1.33, 95\%, CI 1.12 to 1.56). Mothers with advanced age, early neonatal death rate and caesarean section rate were significantly higher than the age group 20-34 (OR 3.33 95\% CI 1.17 to 9.49 and OR $2.1795 \%$ CI 1.92 to 2.44 respectively). In contrast, caesarean section rate was low in teens (OR $0.4495 \%$ CI 0.36 to 0.52 ).
Stillbirth and preterm birth rates were not significantly different (OR 1.36 95\% CI 0.66 to 2.76 and OR $0.9895 \%$ CI 0.83 to 1.15 ) in mothers with advanced maternal age.

\section{Discussion}

Our study demonstrated that complications surrounding teens and advanced maternal age pregnancies are different. It has been shown that nearly $60 \%$ of all girls are married by the age of 18 years and one fourth is married by the age of 15 years in South Asia ${ }^{12}$. Within South Asia, the recorded teenage pregnancy rate is highest in Bangladesh $35 \%$ followed by Nepal $21 \%$ and India $21 \%{ }^{13}$. Recent population study by Tyrberg et al concluded that the annual incidence of teenage births in Sweden decreased significantly from 7.7 to $1.6 \%$ from 1973 to $2010^{4}$. Incidence of teenage pregnancy in our population remained higher $(8 \%)$ than national figure $(6.5 \%)$ for Sri Lanka but lesser than other South Asian countries ${ }^{14}$.

Preterm delivery rate was significantly higher among teens than the normal age group in our study population. Preterm labour is responsible 
for majority of preterm births (PB) and $\mathrm{PB}$ is recognised as one of the main causes of perinatal morbidity and mortality ${ }^{15}$. Mid-trimester cervical length assessment and treatment with natural progesterone if the cervical length is $<1.5 \mathrm{~cm}$ could reduce the preterm labour by $40 \%{ }^{15-16}$. Universal screening for cervical length assessment in mid trimester is still a debate due to high cost implications. However, selective screening of cervical length could be considered in high risk groups such as teenage pregnancy. Tyberg et al further showed teenagers were more likely to deliver normally vaginally (aOR 1.70 (95\% CI 1.64-1.75), less likely to have caesarean section (aOR 0.61 (95\% CI 0.58-0.64), and had a greater risk of delivering prematurely ( $<28$ weeks) (aOR 1.61 (95\% CI 1.31-2.00) $)^{4}$. Goonewardene et al reported that older teenagers (17-19) had a significantly higher risk of delivery before 34 weeks of gestation $(\mathrm{OR}=13.6,95 \% \mathrm{CI}=1.8$ $287, p=0.001)$ with no significant differences in the mode of delivery in southern Sri Lanka ${ }^{17}$. Our preterm labour risk in teenage pregnancy was comparable with above two studies and our caesarean section rates were significantly lower than mothers in normal age range.

The exact mechanism underlying the pathogenesis of adverse pregnancy outcome in older mothers is unclear. However it is associated with a range of adverse pregnancy outcomes ${ }^{14}$. These risks are independent of parity and remain after adjusting for the ameliorating effects of higher socioeconomic status as proven by other studies $^{14}$. Our study demonstrated that caesarean section rate and early neonatal deaths were higher among advanced age group. Recent Finish population study revealed same findings as ours and they reported higher induction, instrumental, or by caesarean section rates in mothers with advanced maternal age ${ }^{15}$.
Main limitations of this study were the retrospective nature and the unavailability of data on antenatal pregnancy complications such as, hypertensive disorders in pregnancy, diabetes anaemia etc. In conclusion risks of pregnancy complications are different from teens and in advanced maternal age. More studies are needed to establish the exact causes of these risks and evaluate management options in these women.

\section{REFERENCES}

1. Nyabo Andersen AM, Wohlfahrt J, Christens P, Olsen J, Melbye M. Maternal age and fetal loss: population based register linkage study. BMJ 2000; 320: 1708-12.

2. Confidential Enquiry into Maternal and Child Health. Why mothers die 2000-2002report on confidential enquiries into maternal deaths in the United Kingdom.

3. Bianco A, Stone J, Lynch L, Lapinski R, Berkowitz G, Berkowitz RL. Pregnancy outcome at age 40 and older. Obstet Gynecol 1996; 87: 917-22.

4. Tyrberg RB, Blomberg M, Kjølhede P. Deliveries among teenage women - with emphasis on incidence and mode of delivery: a Swedish national survey from 1973 to 2010. BMC Pregnancy Child birth. $2013 \mathrm{Nov}$ 9; 13(1): 204.

5. WHO. Maternal mortality ratios and rates: a tabulation of available information. World Health Organisation (3rd edition), Geneva. 1991; Unpublished report.

6. The right to reproductive and sexual health. United Nations Department of Public Information (DPI/1877). 1997; http:// www.un.org/ ecosocdev/geninfo/women/ womrepro.htm, Accessed 06/04/06.

7. Viegas $O A$, Wiknsosastro $G$, Sahagun $\mathrm{GH}$, Chaturachinda K, Ratnam SS. Safe child birth needs more than medical services. World Health Forum. 1992; 13: 59-65.

8. Heffner LJ. Advanced maternal age how old is too old? N Engl J Med. 2004; 351(19): 1927-9.

9. MbuguaGitau G, Liversedge H, Goffey D, Hawton A, Liversedge N, Taylor M. The influence of maternal age on the outcomes of pregnancies complicated by bleeding at less than 12 weeks. Acta Obstet Gynecol Scand. 2009; 88(1):116-8.

10. Dias T, Mahsud-Dornan S, Thilaganathan B, Papageorghiou A, Bhide A. First-trimester ultrasound dating of twin pregnancy: are singleton charts reliable? BJOG. 2010 Jul;117(8): 979-84.

11. Dias $T$, Arcangeli $T$, Bhide $A$, MahsudDornan S, Papageorghiou A, Thilaganathan B. Second-trimester assessment of gestational age in twins: validation of singleton biometry charts. Ultra sound Obstet Gynecol. 2011; 37(1): 34-7.

12. The World Bank. Children and Youth. The World Bank, Washington DC. 2004; Available from: http://siteresources.worldbank.org/ INTCY/Data/20333440/YIN-SA.pdf, Accessed 22/08/08.

13. Mehra S, Agrawal D. Adolescent health determinants for pregnancy and child health outcomes among the urban poor. Indian Pediatrics. 2004; 41: 137-45.

14. Fernando D, Gundawardena N, Senarath U, Weerasinghe M, Galwaduge C, De Silva C.Prevalence, trends and district differentials in teenage pregnancies. Journal of the College of Community Physicians of Sri Lanka. 2011; 16(2): 21-30.

15. To MS, Skentou C, Chan C, Zagaliki A, Nicolaides $\mathrm{KH}$. Cervical assessment at the routine 23-week scan: standardizing techniques. Ultrasound in Obstetrics and Gynecology. 2001; 17(3): 217-19.

16. Fonseca EB, Celik E, Parra M, Singh M, Nicolaides $\mathrm{KH}$. Progesterone and the risk of preterm birth among women with a short cervix. New England Journal of Medicine. 2007; 357(5): 462-9.

17. Goonewardene IM, Deeyagaha Waduge RP. Adverse effects of teenage pregnancy. Ceylon Med J. 2005 50(3): 116-20.

18. Khalil A, Syngelaki A, Maiz N, Zinevich Y, Nicolaides KH. Ultra sound Obstet Gynecol. 2013 Dec;42(6):634-43. doi: 10.1002/ uog.12494. Maternal age and adverse pregnancy outcome: a cohort study.

19. Klemetti R, Gissler M, Sainio S, Hemminki E. Associations of maternal age with maternity care use and birth outcomes in primiparous women: a comparison of results in 1991 and 2008 in Finland. BJOG. 2013 Aug 14. doi: 10.1111/1471-0528. 